\title{
Interpretable Housing for Freedom of the Body: The Next Generation of Flexible Homes
}

\author{
Kyung Wook Seo ${ }^{1}$, Chang Sung Kim ${ }^{2 *}$ \\ ${ }^{1}$ Department of Architecture, Kyonggi University, Suwon, South Korea; ${ }^{2}$ Departmentof Architectural Engineering, Hyupsung Uni- \\ versity, Hwaseong, South Korea. \\ *Corresponding author: Email: cskim815@hanmail.net
}

Received August $1^{\text {st }}, 2013$; revised September $3^{\text {rd }}$, 2013; accepted September $16^{\text {th }}, 2013$

Copyright (C) 2013 Kyung Wook Seo, Chang Sung Kim. This is an open access article distributed under the Creative Commons Attribution License, which permits unrestricted use, distribution, and reproduction in any medium, provided the original work is properly cited.

\begin{abstract}
If we have gone through the first generation of housing design that pursued functional optimization, ergonomics, and circulation efficiency during the last century, now we are living in the second generation where more advanced goals, such as universal design, ubiquitous design, sustainable design, and environment-friendly design, are emphasized. Although this second generation of design focuses upon the wellness of humans in accordance with environment, it still has the attitude that a more precisely designed home can guarantee a better life. What lacks in this approach is the freedom of the body; it needs to make its own choice as to how to use a space. Thus, it is suggested in this paper that what is important in designing a home is to provide alternatives in daily lives so as to make a full exploration of a given space. These alternatives can be made by offering residents an interpretable space where they can figure out space usages and routs in a constantly changing context. Two spatial devices are discussed in depths as a way to realize this interpretable house: room-to-room enfilade and ring spatial structure. By investigating some existing house plans, it is illustrated how they can guarantee the freedom of the body, and thus alternatives for the flexible domestic life.
\end{abstract}

Keywords: Interpretable House; Bodily Freedom; Flexibility; Polyvalency

\section{Introduction: Third Generation of Healthy Home Movement}

The modernist movement in the twentieth century has left a functionalistic legacy that emphasizes the optimal programming of architectural space. Following this trend, the house planning in particular has moved towards a scientific realm where precise analysis and anticipation of economical human movement are sought. Technology has accelerated this movement further, making more efficient building environment that could cut away useless junks of space and combine functions by offering electrical and mechanical devices and installations. In the global perspective, this modern movement of functional optimization, ergonomics, and circulation efficiency has made domestic space more tightly integrated in most parts of the developed world. The UK, for example, has experienced the typical integration process of functional spaces in the early twentieth century; thus, the old spatial division of parlor/living room and dining room/kitchen, which separated formal and public activities from informal and private ones, has given way to a combined func- tional space of living-parlor and dining-kitchen equipped with automated home appliances. The main concern in this modernized home was "running the house rather than social proprieties" and the whole house potentially became a clean display zone [1]. The concept of flexibility and freedom in domestic living was constantly discussed in both practice and research; but it was oriented towards the "rationalistic, scientific ethos of the age" [2].

If we label the above trend of house planning-mainly focusing on efficiency — as the past generation of healthy home design, then what could be the defining characteristics of the current house design movement? The followings are the current issues in the housing design sector:

\section{Universal Design.}

Ubiquitous Design.

Sustainable Design.

Environment-friendly Design.

Some issues seem to be a bit older than the others, but still all of these have become popular topics in the housing industry within the last few decades. They differ in 
their meanings and design strategies, but share a common goal which is "the wellness of humans in accordance with environment"; and we may call this new trend as the second generation of healthy home environment. With no doubt, the concept of this current movement of home design is more advanced one, since they begin to embrace those factors neglected by the first generation: caring of non-standard humans, the increased sensibility in automation system, coping with the life cycle of home, and preservation of natural environment. It is certain that all these concerns are very timely since they would become increasingly crucial factors in the years to come. What lacks in them, however, is the fundamental concern about the inherent socio-spatial dimension of the house and its implication on the way we live; all of those issues treat the architectural space merely as an inert entity that simply follows functional requirements. Even the sustainable design, which includes this agenda in its broad meaning of the term, limits itself by vaguely suggesting the possibilities of spatial transformation of the house. In a sense, all these current issues still maintain the attitude of the first generation that a more precisely programmed house can guarantee a better life.

Considering above situations, the main theme of this research has sprouted: the freedom of the body, or rather bodily choices in domestic life, which has been halfforgotten during the course of housing evolution. It is not about the old concern for the flexible plan or the transformable house, but about the role of spatial settings in housing to liberate the bodily freedom to make a home interpretable. In a broad sense, it is about the anthropology of the human body in relation to the sociology of built environment. In what follows, it is argued that this issue presumably would emerge as the central point in the third generation of healthy home environment.

\section{Polyvalency and the Levels of Living Frames}

The issue of flexibility or adaptability is not new; it has constantly discussed in practice and education throughout the twentieth century. On a small scale, it could be applied to a single house level by providing movable partitions as in Schröder house, and on a bigger scale, to a mass construction level by utilizing the frame/infill concept as represented by SAR method. My definition of adaptability, however, is a bit different.

Architects have known for decades about another mode of adaptability, since Dutch architect Herman Hertzberger first used the term polyvalency in 1962. It means that a building can be used in different ways without adjustment to the way it is built [3]; thus it can be a more viable architectural feature than the movable partition in Schröder house or infill structure in SAR method when exposed to a long passage of time. Austra- lian architect, Stefan Picusa clarified the concept of polyvalency by contrasting two kinds of adaptabilities, namely inherent adaptability and potential adaptability [4]. According to him, the former is "built into the initial design, giving the occupant choice through intentional ambiguity, within fixed physical constraints of a given plan" while the latter is achieved by "technically providing flexible spatial features like verandahs, undercrofts, roof spaces, and, more recently, demountable partitions and movable fittings" [4]. By inherent adaptability, he expressed exactly the concept, polyvalency. In the last century, however, it has received far less attention than potential adaptability [5], probably due to the modern functionalist spirit that everything, including adaptability, should be designed by the mighty hands of architects. For them, polyvalency in architectural space must have been felt as passive, neutral, and arbitrary. In the new millennia, however, its importance is slowly spreading out.

The term, "polyvalent" as an adjective, or "polyvalency" as a noun, would be used throughout this paper. However, it is not used simply at the level of architectural space but at the other levels including furniture and entire building as a block. Therefore, I will label any built structure as polyvalent if it could be utilized in more than a single way based on users' interpretations.

John Habraken distinguished five hierarchies of built environment: road network, building, partitioning, furniture, and body and utensil [6]. These levels represent a hierarchical enclosure system wherehigher levels regulate and affect the form of lower levels; thus, any analysis on one level cannot stand alone without the others. In this research, they would be reduced to four: building, partitioning, furniture, and body. If we evaluate these four levels in terms of speed, they would be ranked as in Table 1.

Above time scales and speeds are symbolic and relative idea, but it is evident that the higher the level, the lower the speed. As the building and the body are located in two extreme ends of the order, it seems natural that there is no way for the static building to catch up with the changing needs of the body through the passage of time; and this could be more so in the case of standardized

Table 1. Speed of the four levels.

\begin{tabular}{cl}
\hline Level & \multicolumn{1}{c}{ Speed } \\
\hline 1 & $\begin{array}{c}\text { Buildings can stay on its site for more than 100 years } \\
\text { Partitioning, if there is no urgent need for change, } \\
\text { more than 10 years }\end{array}$ \\
3 & Furniture, if properly positioned, more than 1 year \\
4 & Body, in any circumstances, less than 1 minute \\
$\begin{array}{c}\text { Speed } \\
\text { rank }\end{array}$ & Building < Partitioning $<$ Furniture $<$ Body \\
\hline
\end{tabular}


multi-unit housing which blindly attempts to accommodate a wide spectrum of lives in a small number of unit types.

Therefore, the main argument of this research would be based on this point: any pre-determined, or rather pre-fixed program of built structure cannot cope with the changing needs of human behavior, and thus, at some point, has to restrict the freedom of the body. In what follows, two of the above levels, those of furniture and partitioning, are discussed in detail. An argument would be made that modern furniture restricts the freedom of the body posture, and the programmed partitioning restricts the movement of furniture or rather spatial function. These two, combined, restricts the freedom of the body.

\section{Programmed Partitioning and Human Movement}

Looking at the old precedents of housing around the world, one can find that the rooms are generally for multi-purposes, and activities in a room can be transferred to other rooms without much conflict. The Palladian villa in Figure 3 shows how this was possible. Rooms have plural number of access openings that lead to other rooms, not to a corridor or a central hall. When a row of rooms are directly connected sequentially like this, it makes a spatial configuration known as a "room-toroom enfilade”. It is suggested here that this enfilade is an effective spatial device that can generate an enhanced degree of flexibility in space use as in Palladian villas. When two rooms of similar sizes are placed next to each other and directly accessed, they could support each other by accommodating similar activities when needed. When three rooms of comparable sizes are directly attached and accessed in a row, the room in the middle can support the two in each end. In this case, due to its innate ambiguity, this room can have a higher degree of adaptability; it can be a central zone that integrates the three or act as a mere buffering zone. This is how the enfilade works for polyvalency; since a room can readily support the adjacent one, activities are interchangeable. In this circumstance, a resident can perform the same activity in a different position; and thus his or her body is free from designated functions in space, and so does furniture.

If the room-to-room enfilade makes a ring-shaped spatial structure that can allow an unending circular movement, then the freedom of movement and the freedom of activity allocation is maximized as in Palladian villas; it generates a strong degree of polyvalency in the house. In the modern house, however, the ring structure is hard to be realized. This is because the modern home is becoming a container of an ever growing number of furniture that needs to be in touch with wall surface, and the ring structure requires at least two openings for each room by sacrificing wall surface. Nevertheless, as long as rooms can allow it, the ring shaped spatial structure could be another strong device to induce polyvalency.

The use of the enfilade in the plan can be regarded as one of the defining characteristics of private houses. Gilles Barbey noted that the difference between the residential housing and the institutional housing, such as prison, dormitory, and monastery, can be seen by the dominant use of the enfilade in the former and the corridor in the latter for the distribution of space [7]. Considering the fact that the residential housing needs a higher degree of adaptability than the institutional housing, in order to accommodate a wide spectrum of living patterns and their changing needs in time, this seems a natural design solution. In the twentieth century, however, we have observed that more and more houses adopt the corridor for the flow distribution, unlike their old counterparts. What could be the consequences of this transformation in these modern houses?

In the seventeenth century UK, there appeared a passage in the middle of the house plan as in Figure 1. By using this new spatial device, a direct access to a room from the public zone, without passing through other private rooms, was made possible. Followingly, access routes in the house were made simple and easy with improved privacy, while sacrificing the route choice by the users. According to Robin Evans, the evolution of the house plan towards a more privacy-oriented arrangement by means of the corridor is to facilitate "purposeful communication" while reducing "incidental communication" between rooms and residents [8]. Yet, in the light of polyvalecy, "incidental" could be more valued than "purposeful"; it is not the "programmed" route but the "incidental" route that can generate a new possibility of spatial use-a passive way of increasing the freedom of the body.

The use of the corridor certainly diminishes the interchangeability of activities that "requires a wide range of possible connections for services” [9]. In other words, the modern plan layout where a multiple number of rooms are exclusively accessed from a single room, i.e. the corridor or a central hall, cannot support the polycalency in life, because this type of plan is "less capable of being adapted to suit different living patterns" [3].

As described above, there is an evident tendency that the room-to-room enfilade enhances activity interchangeability, while the corridor does not. Based on this line of thought, it may be said that the degree of polyvalency can be measured, to a certain degree, by investigating the usage of the corridor in a given plan. Figure 2 shows the urban traditional house in Seoul, Korea that prevailed between the 1930s and 1950s. Here, the central courtyard directly links other rooms, making the enfilade without corridors, and also maru - a space with raised wooden 


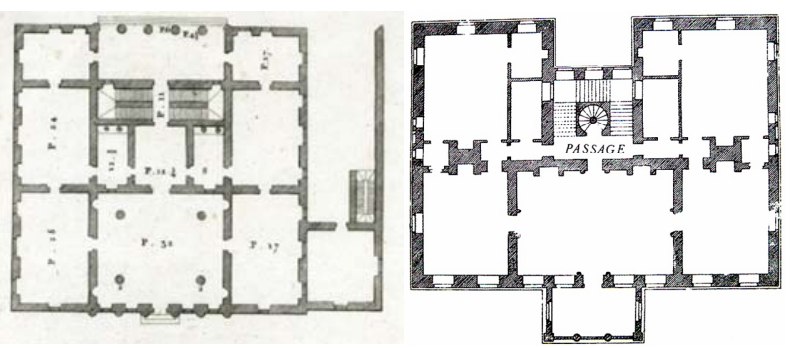

Figure 1. Palazzo Antonini (1556, left) by Andrea Palladio and Amesbury house (1661) by John Webb.

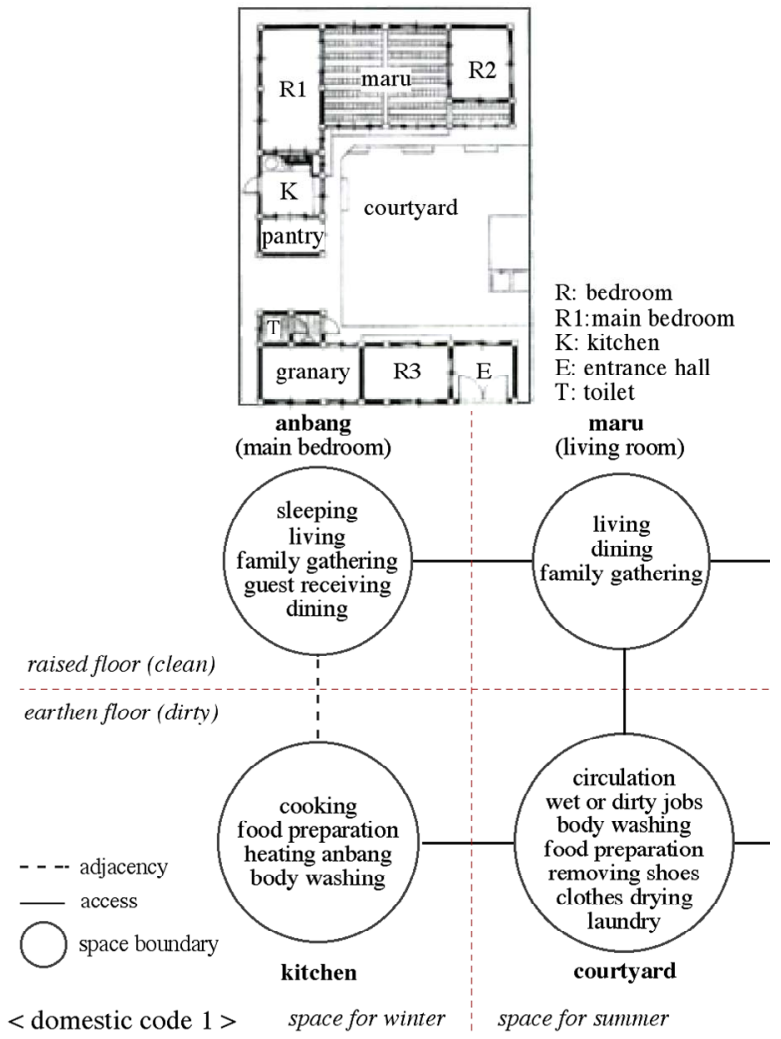

Figure 2. Urban traditional house and its activity diagram [10].

floor-offers the enfilade approach to other two bedrooms on both sides. On the right side is the diagram that shows the four spaces-anbang, maru, courtyard, and kitchen-linked together, and the activities executed in the rooms.

It is found that anbang and maru support each other with the functions of living, dining, and family gathering, and kitchen and courtyard with those of food preparation and body washing. Without corridors or other transient space for circulation, the enfilade structure of this house could offer the freedom of living in relation to time, seasons, and personal choices.

Figure 3 shows the apartment house plan in Seoul in the 90s. As all the circulation movements are concentrated in the central hall, which is marked $\mathrm{H}$ in the plan, this space performs the role of a corridor. This hall space can be seen, at first sight, as a part of the living room, since it is open to it without partitions. However, it is evident that its function as a distribution core clearly distinguishes this space from the living room zone. The diagram on the right also confirms this fact. The central hall links all the access relations from the middle of the house; therefore, residents have to go through this traffic center to move to other spaces in the house. In this type of house plan, it may be hard for a room to support the activities of the other room as in the urban traditional house.

During the transformation process of the apartment houses, there were plans that still preserve the room-toroom enfilade as shown in Figure 4.

In these plans the living room and the anbang were directly connected, and thus each could support the other. As the number of furniture grows in the house, the characteristics of each space were defined more specifically.
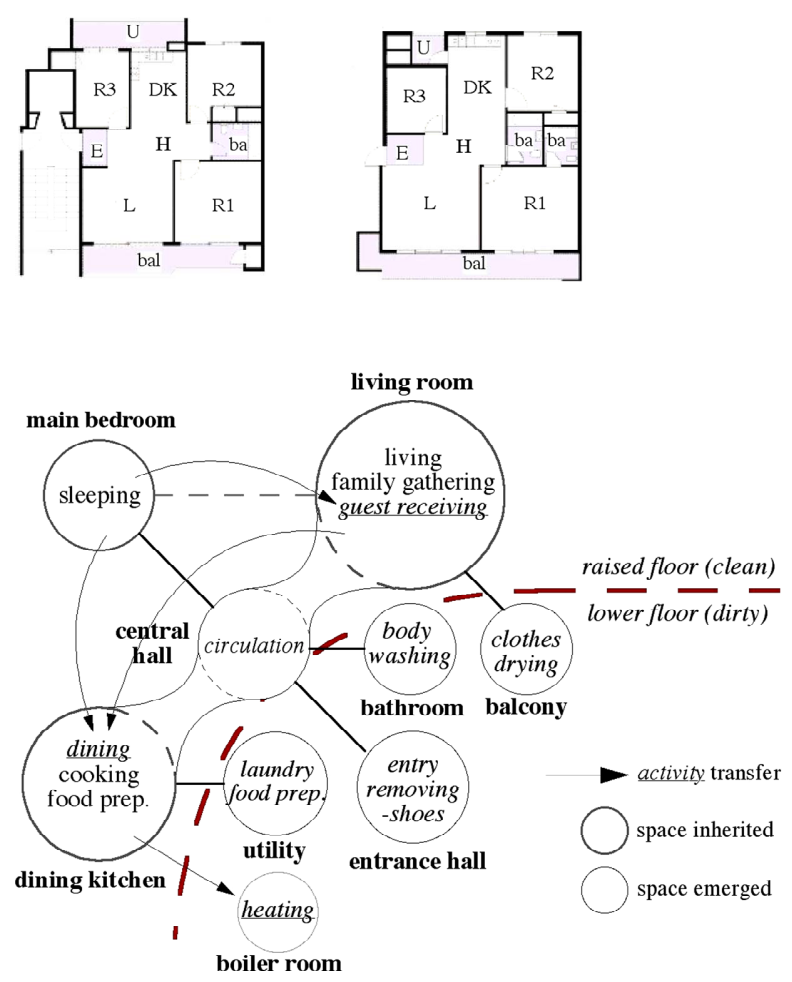

Figure 3. Typical apartment house plan in the 1990s [10].

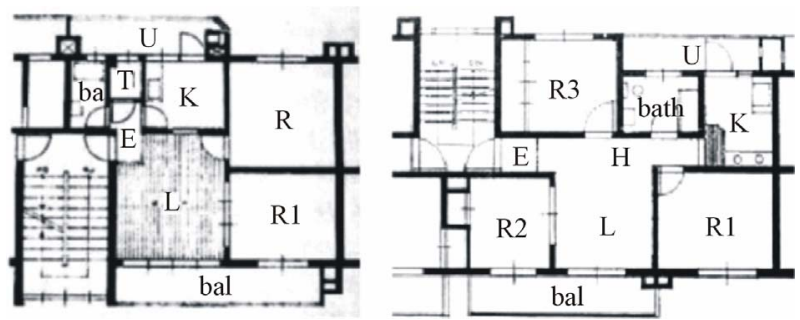

Figure 4. Earlier apartment house plans in the 1960s. 
Therefore, each room had to be more independent, performing specialized functions, and it needed more wall surfaces. All these change demanded, as a convenient solution, the central corridor as a powerful integrator of circulation.

In sum, Korean houses have evolved from the enfilade to the corridor; from interchangeability to fixed function; from a personal choice of living to a pre-determined living. The corridor certainly reduced the possibility of polyvalence, and even those early apartment plans that still preserved the enfilade gradually disappeared.

This observation can be further corroborated by investigating multi-unit houses with different size. Figure 5 shows five staircase access plans with different number of bedrooms and their corresponding graph representations. They are the most widely used plans in Metropolitan Seoul between 1962 and 1990 according to Kim and Park's study [11]. Pointing out that in Seoul a small number of typical plans are repeatedly produced, they argued that these plans are designed in the same manner regardless of their sizes. Below each plan is the graph developed by this author to effectively show the access and adjacency relations of rooms. In the graph, rooms are represented by bubbles, and access and adjacency relations between them are represented by continuous and dotted lines respectively. The gray rectangular box means the interior area and thus balconies or utilities are generally positioned outside of it. This graph-theoretic representation, thus, can explain both geometrical and topological properties of the plan in a single standardized format.

What these graphs reveal is that all the plans of different sizes have one prominent feature; most of the rooms are connected to or through the central hall which is marked " $\mathrm{H}$ ". Now, no enfilade and no ring structure can be seen in the people's house in Seoul, and the chance to experience the possibility of bodily freedom has disappeared.

\section{Discussion and Conclusions: Polyvalent Houses}

What is suggested in this section is the theoretical ways of making polyvalent houses. Some good examples are analyzed to find out their spatial logic. Table 2 shows two different ways of making enfilades in the house. A house needs to have service spaces which can make a core. When the core is placed in the middle, the enfilade is made that will automatically form a ring. Another way is to put the split cores on each side in order to provide a central hall that is connected to other rooms in an enfilade ways. This, however, do not provide rings. When enfilades are combined with rings, their effects are multiplied. Dapperbuurt house in Table 3 shows how this simple house can have 14 different sets of routes by closing or opening the movable partitions or doors. Compared to this, Pieter Vlamingstraat house at the bottom of Table $\mathbf{3}$ has only three variations in the route choices due to the position of the core on each side; the cores block the ringy structure of space.

To make a ring in the house, it is necessary that at least one partitioned space has two access points or two doors. This, however, is a local structure that does not have a big impact to free the functional fixation of the house. It is better to have a global ring that connects rooms in the periphery of the house. The two basic ways in Table 2 show why central core is more effective in creating enfilades and rings. However, the central hall type can also be made to provide rings as well as enfilades.

In Table 4, the plan above makes a ring around the
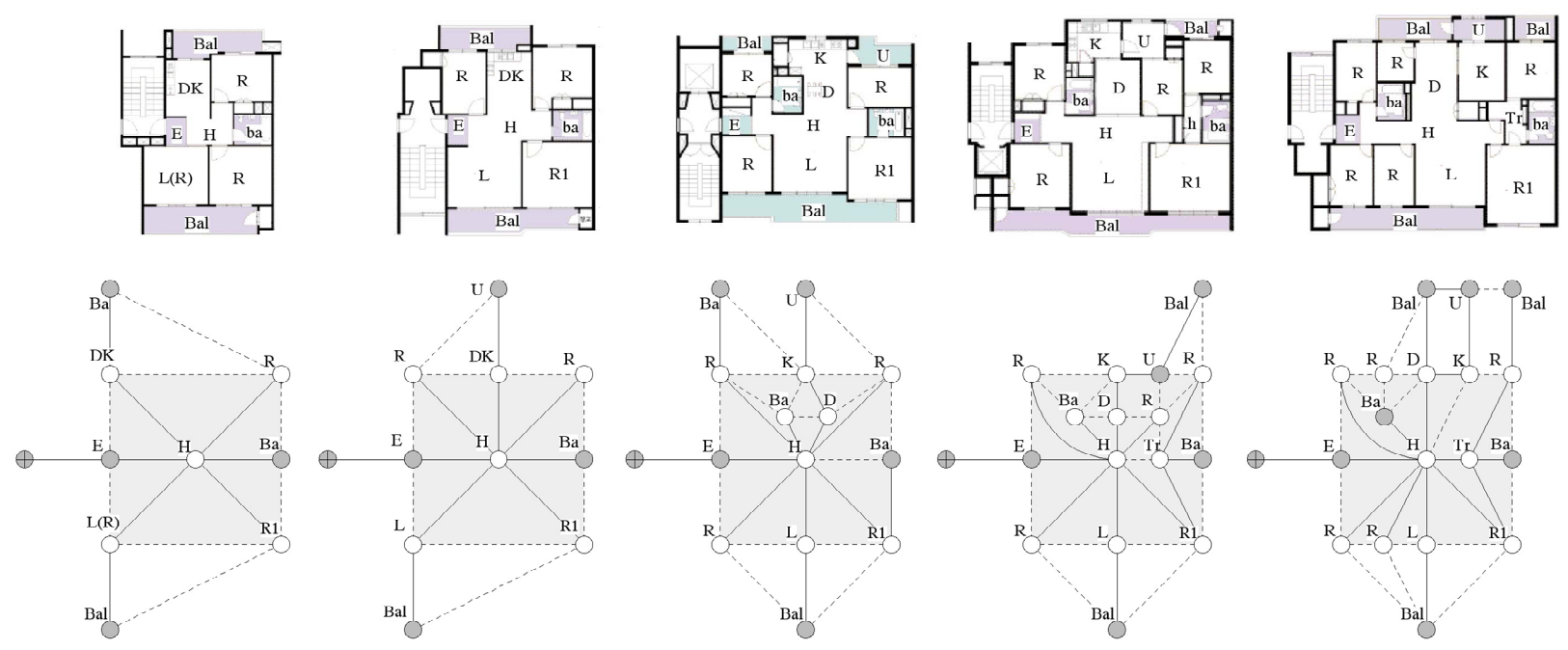

2 bedroom plan

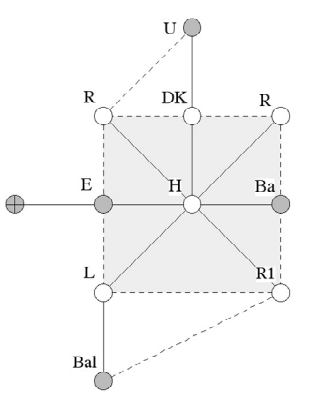

3 bedroom plan

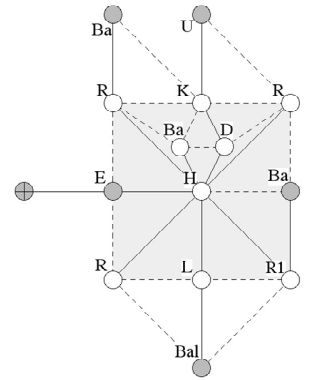

4 bedroom plan

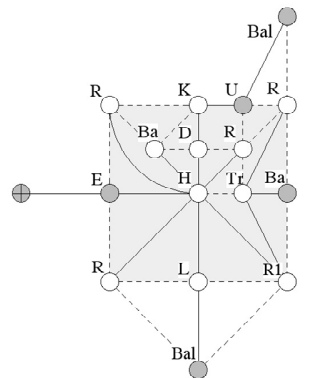

5 bedroom plan
6 bedroom plan

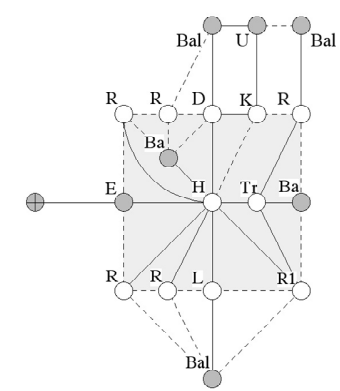

Figure 5. The most popular staircase type plans in Seoul between 1962-1990 [12]. 
Table 2. Two Basic ways of making enfilades [13].
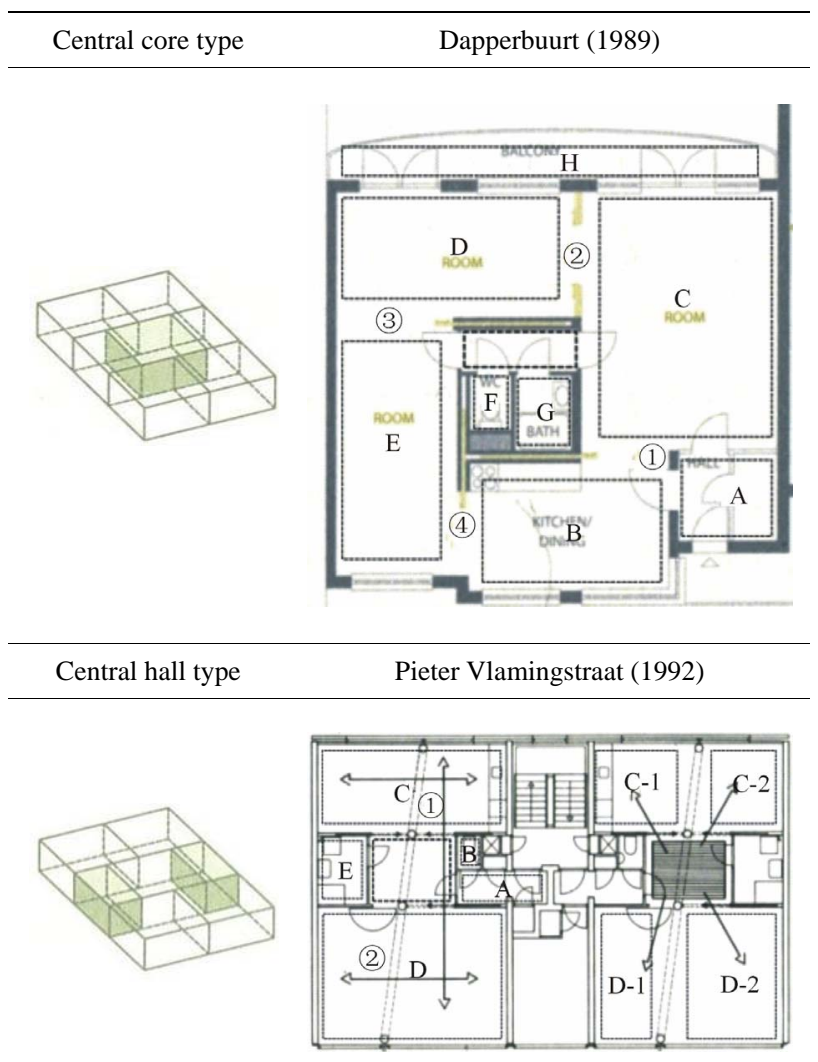

central hall by placing two doors on each side and sliding partitions between them. In the plan below, central hall is sub-divided by service installations and discontinuous walls within the unit. This plan thus provides many local rings as well as global rings.

This research attempted to illuminate the forgotten usability of the inherent adaptability which is against the tight-fit space programming of the modern functionalists who insist on the "form follows function" attitude.

It is when this deterministic characteristic of domestic space is dissolved that the pre-condition for the freedom of the body, which allows more fluid and contingent functional possibilities, could be established.

We can choose our own route in urban settings but not in modern domestic settings. Through the process of housing evolution, we have lost, consciously and unconsciously, the freedom of bodily move and the freedom of bodily posture. Some propositions can be made for the recovery of bodily freedom in the house as in Table 5 .

These five hierarchies of remedy reflect the levels in architecture, from a body to a building in the increasing order. If these strategies are more carefully evaluated for the design of housing, then we can build a healthy home in the deepest meaning of it. The healthy housing design is the one that encourages the various type of bodily movement, without restricting it in the name of move-
Table 3. Comparing possible routes between two types.

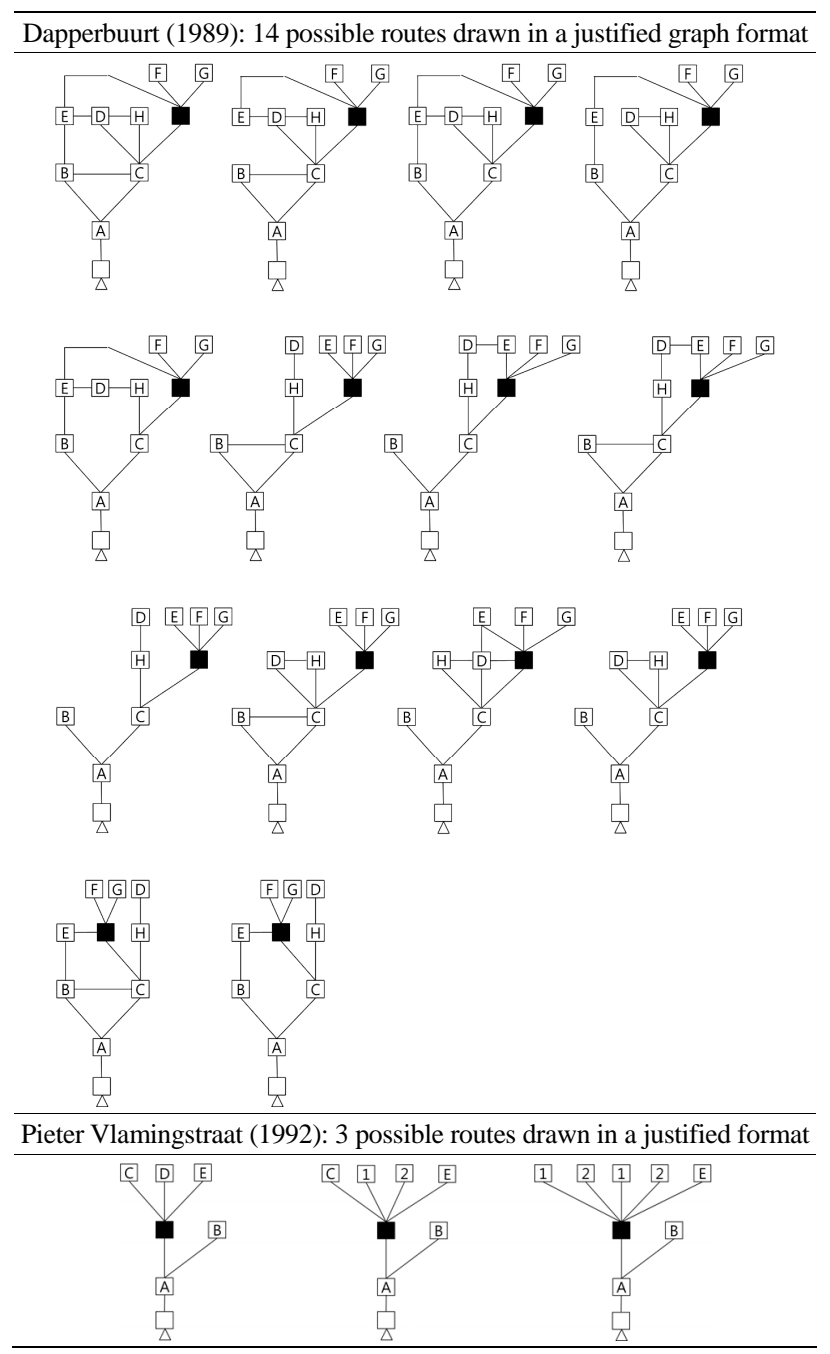

Table 4. Two alternative ways of making rings [14].

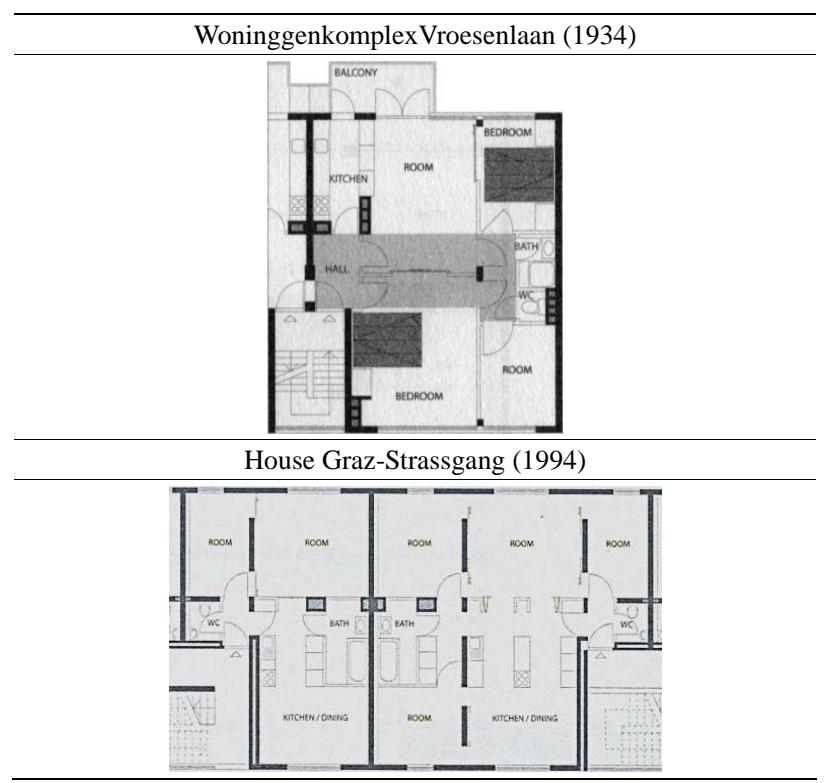


Table 5. Hierarchies of remedies for bodily freedom in the house.

\begin{tabular}{ccc}
\hline & Hierarchies of Remedy & Hierarchies of Bodily Freedom \\
\hline 1 & $\begin{array}{c}\text { Recognition of } \\
\text { postural potentials } \\
\text { Re-evaluation of }\end{array}$ & Freedom of using muscles \\
2 & "sitting furniture" shapes & Freedom of making postures \\
3 & $\begin{array}{c}\text { Renovating the power } \\
\text { supply installations } \\
4\end{array}$ & Freedom of locating wired duties \\
& $\begin{array}{c}\text { Re-thinking of } \\
\text { function-fixed rooms } \\
\text { Re-evaluation of } \\
\text { building circulation }\end{array}$ & Freedom of distributing activities \\
& Freedom of selecting routes in \\
\end{tabular}

ment optimization and functional convenience.

\section{Acknowledgements}

This research was supported by Basic Science Research Program through the National Research Foundation of Korea (NRF) funded by the Ministry of Education, Science and Technology (NRF-2011-0012359).

\section{REFERENCES}

[1] A. Ravetz, "The Place of Home: English Domestic Environments, 1914-2000,” E \& FN Spon, London, 1995, pp. 166-167.

[2] S. Muthesius and M. Richardson, "Continuity and Change," The Transformable House, John Wiley \& Sons Limited, Hoboken, 2000.

[3] B. Leupen, “Towards Time-Based Architecture,” 010 Publishers, Rotterdam, 2005.
[4] S. Pikusa, “Adaptability,” Architecture Australia, Vol. 72, No. 1, 1983, pp. 62-67.

[5] R. J. Lawrence, "Housing, Dwellings and Homes: Design Theory, Research and Practice,” John Wiley \& Sons Limited, Hoboken, 1987.

[6] N. J. Habraken, “The Structure of the Ordinary," MIT Press, Cambridge, 1998.

[7] G. Barbey, "Social Space in Residential Environments: the Importance of Spatial Archetypes and Their Implication for Design,” Progetto Finalizzato Edilizia, Milano, 1992.

[8] R. Evans, "Translations from Drawing to Building and Other Essays," Architectural Association Publications, London, 1997.

[9] F. Bijdendijk, “Solids,” In: B. Leupen, Ed., Time Based Architecture, 010 Publishers, Rotterdam, 2005.

[10] K. W. Seo, "The Law of Conservation of Activities in Domestic Space," Journal of Asian Architecture and Building Engineering, Vol. 5, No. 1, 2006, pp. 21-28. http://dx.doi.org/10.3130/jaabe.5.21

[11] S. Kim and Y. Park, "Inflexible Pattern of Apartment Unit Plan: The Comparative Analysis of the Public and Private Sector Apartment-III," Journal of Architectural Institute of Korea, Vol. 8, No. 7, 1992, pp. 73-83.

[12] K. W. Seo, "Space Puzzle in a Concrete Box: Finding Design Competence That Generates the Modern Apartment Houses in Seoul," Environment and Planning B: Planning and Design, Vol. 34, No. 6, 2007, pp. 10711084. http://dx.doi.org/10.1068/b32134

[13] B. Leupen and H. Mooij, "Housing Design: A Manual,” NAi Publishers, Rotterdam, 2012.

[14] T. Schneider and J. Till, "Flexible Housing," Architectural Press, Oxford, 2007. 